\title{
Georges Didi-Huberman, Ninfa profunda - Essai sur le drapé-tourmente
}

\section{Valentina Ponzetto}

\section{(2) OpenEdition}

10 Journals

\section{Édition électronique}

URL : https://journals.openedition.org/studifrancesi/21441

DOI : 10.4000/studifrancesi.21441

ISSN : 2421-5856

Éditeur

Rosenberg \& Sellier

\section{Édition imprimée}

Date de publication : 1 décembre 2019

Pagination : 589-590

ISSN : 0039-2944

\section{Référence électronique}

Valentina Ponzetto, «Georges Didi-Huberman, Ninfa profunda - Essai sur le drapé-tourmente », Studi

Francesi [En ligne], 189 (LXIII | III) | 2019, mis en ligne le 01 mars 2020, consulté le 11 novembre 2021. URL : http://journals.openedition.org/studifrancesi/21441 ; DOI : https://doi.org/10.4000/

studifrancesi.21441

Ce document a été généré automatiquement le 11 novembre 2021.

\section{(c)}

Studi Francesi è distribuita con Licenza Creative Commons Attribuzione - Non commerciale - Non opere derivate 4.0 Internazionale. 


\title{
Georges Didi-Huberman, Ninfa profunda - Essai sur le drapé-tourmente
}

\author{
Valentina Ponzetto
}

\section{RÉFÉRENCE}

Georges Didi-Huberman, Ninfa profunda - Essai sur le drapé-tourmente, Paris, Gallimard, 2017, «Art et artistes», 41 illustrations couleur, 150 pp.

1 Entièrement consacré à l'imaginaire visuel de Victor Hugo romancier et dessinateur dans cette zone trouble et hautement métaphorique où se rencontrent la figure féminine et l'élément aquatique, ce volume est le troisième d'une série qui en comprend à ce jour quatre: en amont, Ninfa moderna. Essai sur le drapé tombé (2002) et Ninfa fluida. Essai sur le drapé-désir (2015) et en aval le très récent Ninfa dolorosa. Essai sur la mémoire d'un geste (2019), tous parus dans la même collection.

2 Le point de départ pour cet Essai sur le drapé-tourmente réside dans l'idée qu'on trouverait dans toute l'œuvre de Victor Hugo «une étrange correspondance» et presque une équivalence entre regarder une femme en la désirant et «sombrer dans un fluide», identifiable de préférence avec les profondeurs d'un océan, quand ce n'est avec «ses propres gouffres psychiques»(p.7). Pour le philosophe, Hugo aurait donc rendu indissociables «les trois motifs de la femme comme enjeu du désir, de la mer comme milieu de la lutte et, enfin, de la mort comme destin commun au désir et à la lutte» (p. 8).

3 Ces motifs sont d'abord suivis à travers le regard et le destin de Gilliatt et de Gwynplaine et les méandres les plus luxuriants de métaphores et d'images saisissantes des Travailleurs de la mer et de L'Homme qui rit. Les audaces techniques de la plume hugolienne se retrouvent également dans son œuvre graphique, notamment dans ses célèbres dessins au lavis d'encre, au fusain et à la gouache, dont de nombreux exemples illustrent le volume: odalisques, pieuvres, vagues océanes, paysages surgissant des brumes, ou simples taches, dont Hugo avant Rorschach semble avoir perçu le potentiel de révélateur psychique. Le «voyage dans la texture» devient ainsi voyage 
psychophysique à travers les plis multiples d'un corps féminin, d'une draperie ou d'une mer agitée, dans une entrée en matière toujours recommencée. Le «drapé tourmente» du titre n'est dès lors pas seulement un effet pictural, une expérience de physique des fluides avec les fameuses «taches-pliages» ou une manière imagée et romantique de décrire la nature déchainée. Ce qui émerge, c'est surtout le tourment de l'âme, "car l'âme elle-même est une draperie, dont les «spectres» hugoliens savent si bien dessiner les mouvement erratiques». Si bien que la question liminaire et fondamentale posée par cet essai: «que se passe-t-il, pour Hugo, entre voir une femme et sombrer dans un fluide?» pourrait se reformuler «à un niveau plus morphologique et métapsychologique à la fois: que se passe-t-il, pour Hugo, entre la psyché du mot tourment et la physis du mot tourmente?» (pp. 51-52). Le dessin ou l'écriture arrivent ainsi à concentrer de manière fantasmatique les angoisses de l'auteur. Didi-Hubermann nous invite dès lors à penser l'œuvre hugolienne plutôt en termes philosophiques d'immanence, dans un jeu de références qui va de Lucrèce à Deleuze en passant par Spinoza. "L'immanence ellemême travaille à confondre toutes les échelles» (p. 109), conclut le critique et les choses vues par Hugo (avec allusion transparente au recueil de notes et mémoires posthumes du poète) «délivrent une vérité insue, non subjective, alors même qu'elles ont été investies de cette dilatation hypocondriaque faisant de tout objet extérieur un mouvement organique touchant aussi à l'intérieur» (pp.117-118), ce mouvement de vague hypocondrique qui donne de manière vaguement énigmatique son titre au dernier chapitre. "Voilà pourquoi il est poétique, mais pas faux de décrire un tourment psychique comme une tourmente physique, de contempler une femme comme on plonge dans une tempête, ou de regarder une tempête comme on surprend un acte sexuel» (p. 109).

4 Malgré l'impeccable documentation et la puissance de l'analyse on a en fin de compte l'impression d'une approche et d'une écriture extrêmement personnelles, voire intimes, comme si Didi-Hubermann regardait toutes les œuvres de Victor Hugo à la manière des taches de Rorschach: comme un canevas où projeter ses propres obsessions et ses propres fantasmes. 